\title{
Cost Determinants in Canadian Universities
}

\section{VAUGHAN DICKSON*}

\begin{abstract}
The relationship between costs per student and enrollment is examined with regression analysis for 61 Canadian universities for the academic year 1986-87. This relationship is explored for overall costs and for sub-components including instruction, library, computing, administration and physical plant costs. Also examined is the influence on cost per student of student mix, student-faculty ratios, faculty wages and research intensity. Among the conclusions are that economies of scale apply to Canadian universities and costs per student are positively related to faculty salaries, faculty research intensity and the proportion of students in graduate programs and scientific disciplines.
\end{abstract}

\section{Résumé}

La relation entre les coûts par étudiant et la taille des clientèles de 61 universités canadiennes pour l'année académique 1986-87 a été étudiée en employant la méthode de régression multiple. Spécifiquement, la corrélation entre les clientèles et les coûts totaux a été examinée de même que les composantes de ces coûts, soit les coûts d'enseignement, des services de bibliothèque et d'informatique, les coûts administratifs et les coûts des bâtiments et terrains. On a également analysé la relation entre la composition des clientèles, la proportion étudiant/professeur, les salaires du corps professoral et l'intensité de la recherche, et les coûts par étudiant. L'étude démontre qu'il existe des économies d'échelle dans les universités canadiennes, ainsi qu'une corrélation

* University of New Brunswick 
positive entre les coûts par étudiant et les variables qui portent sur les salaires des professeurs, l'intensité de la recherche, et la proportion d'étudiants inscrits aux programmes d'études supérieures et dans les disciplines scientifiques.

Universities are an important feature of the Canadian economy with university expenditures accounting for about 1.5 percent of GNP. Notwithstanding the significance of the university sector, however, there has been little work done on the determinants of cost within Canadian universities. 'This paper addresses part of this deficiency by estimating, for the academic year 1986-87, cost functions relating costs per student to enrollment and other variables for 61 institutions accounting for 92 percent of Canadian university enrollment. As far as can be determined, no cost function studies have been done for Canada. ${ }^{2}$ In contrast, U.S. research reveals a substantial body of work (see Brinkman and Leslie 1986) survey concerned with economies of scale in higher education.

Among the questions asked are what is the importance of economies of scale, (i.e., do costs per student fall as enrollments increase and, if so, by how much?). What components of cost are most responsible for any scale economy effects? How are costs per student influenced by student-faculty ratios and the percentage of students enrolled in graduate school and scientific disciplines? How are costs influenced by the research commitment of faculty?

To answer these questions, regression analysis related university cost per student to enrollment and control factors measuring types of enrollment, research intensity, student-faculty ratios and average faculty salaries. Similar regressions were also run for various cost sub-components, including instructional costs, library costs, computing costs, administration and general costs and the cost of maintaining and operating physical plant.

To summarize, the results indicate economies of scale exist throughout the observed range of enrollment. Predicted cost per student at a large university with enrollment four times the average is 1.2 percent lower than at the arithmetic mean for enrollment and 6 percent lower than for a representative small university with enrollment at one-quarter of the mean. In addition, costs per student are positively related to faculty wage rates, faculty research intensity and the proportion of students in post-graduate programs and scientific disciplines. Higher student-faculty ratios result in lower costs per student. The following discussion presents the sample and the data, regression model, results and conclusions. 


\section{Sample Size and Data}

The sample consisted of 61 Canadian universities for which data on costs and the other control variables could be located for the academic year 1986-1987. The most important source is an annual document on university expenditures and income, Financial Statistics of Universities and Colleges, prepared for the Canadian Association of University Business Officers (CAUBO) by Statistics Canada (CAUBO, 1987). From this document, total costs are defined as the sum of the following kinds of spending: general operating expenditures, special purpose and trust expenditures, sponsored research and ancillary enterprises. General operating expenditures include the cost of instruction and non-sponsored research, library costs, computing costs, administration costs, physical plant operation and maintenance costs, and the cost of student services. ${ }^{3}$ Capital cost figures associated with depreciation of buildings and equipment were not included and are not generally available.

In addition to information on costs, data on university enrollment, categories of enrollment, research intensity, student-faculty ratios and average faculty salaries were also required. Except for the research measure which was constructed using CAUBO data, the required information is available from Statistics Canada publications listed in the references. More detail on the construction of these variables will follow the introduction of the regression model. The sample size included all those universities for which data on all the relevant variables could be obtained.

\section{The Regression Model}

The form of the cost function adopted follows Robidoux and Lester (1988) who estimated unit non-capital cost functions for Canadian manufacturing industries. The representative equation to be estimated has the following general form:

$$
l a c=a+b e+c(1 / e)+d_{0} w+d_{1} s f+d_{2} r f+d_{3} p g p+d_{4} l a b p+d_{5} p t e p
$$

In the above equation, lac is the natural logarithm of average cost per student where average cost is total costs divided by total enrollment. The variable $e$ represents full-time enrollment; $w$ represents average faculty wage; $s f$ is the ratio of students to faculty; $r f$ is research per faculty member; $p g p$ is the percentage of enrollment that is post-graduate; labp is the percentage of enrollment that is in a laboratory discipline; and ptep is part-time enrollment expressed as a percentage of full-time enrollment. The construction of all except labp and $r f$ is straightforward. 
The variable labp was based on data from Statistics Canada (1990) which contains enrollment data for eight field categories. These are: (a) agriculture and biological sciences; (b) engineering and applied sciences; (c) health professions and occupations; (d) mathematics and physical sciences; (e) education; (f) fine and applied arts; ( $g$ ) humanities and related disciplines and; (h) social sciences and related disciplines. The percentage of students in the first four categories is labp. The variable $r f$ is the value of sponsored research dollars per faculty at each university. The figures used are the sum of four sources of sponsored research listed in CAUBO (1987): federal grants, provincial grants, non-government grants, and fees and bequests.

In the above equation, the enrollment variables are meant to capture economies of scale while remaining variables control for other influences on average cost per student. Concerning scale economies, if coefficients $b$ and $c$ are both positive then average cost per student first fall as enrollments increase (economies of scale exist) and then rise (diseconomies of scale exist). In fact, in the regression analysis the coefficient $b$ was persistently insignificant so that the regression results reported contain only the enrollment variable $1 / e{ }^{4}$ The coefficient of this variable was positive and significant, indicating economies of scale throughout the range of observed enrollments.

The control variables are mostly self-explanatory. Average cost per student should increase when average faculty salaries are higher, whereas higher student-faculty ratios should mean lower unit costs..$^{5}$ The variable $r f$ is an imperfect proxy for research emphasis with the expectation that costs per student will be higher in institutions that devote more time and effort to research. ${ }^{6}$ The variables $p g p$ and $l a b p$ are included because it is expected that these enrollment categories are more expensive. Finally, ptep captures the extra cost incurred by institutions with relatively large part-time enrollment. ${ }^{7}$

While our main concern was overall economies of scale, we also explored which sub-components of cost were most responsible for any observed scale effects. Accordingly, five alternative versions of equation (1) were estimated. These replaced lac with the log of library costs per student (llib), the log of computing costs per student (lcom), the log of administration and general costs per student (ladm), the log of physical plant maintenance costs per student (lphy), and the log of instruction and non-sponsored research costs per student (linstr).

One problem is that not all of the control variables are applicable to these cost sub-components. For example, average faculty wages would probably not influence physical plant costs. However, to facilitate comparisons and simplify, 
we retained all the control variables even though not all are appropriate for each cost variable. The mean and standard deviation for all the cost variables (unlogged) and other variables used in the regression analysis are given in Table 1.

Before introducing the results, two problems in applying cost function analysis to universities should be mentioned. First, the use of enrollment as a common measure of output across universities implicitly assumes that different institutions produce equally accomplished students. Obviously, this may not be the case, although in Canada the differences among institutions may not be large compared to the United States. Furthermore, any differences may be due less to differences in teaching effort across institutions and more to differences in the average abilities of respective student bodies. Finally, teaching quality is partially accounted for by the student-faculty ratio.

Another problem in cost function analysis is the assumption that all institutions strive equally to minimize expenditures. One example of this problem is

Table 1

Description, Mean and Standard Deviation of Variables

\begin{tabular}{llcc}
$\begin{array}{l}\text { Variable } \\
\text { Symbol }\end{array}$ & \multicolumn{1}{c}{ Description } & Mean & $\begin{array}{c}\text { Standard } \\
\text { Deviation }\end{array}$ \\
\hline ac & cost per student* & 15.21 & 12.38 \\
$\mathrm{e}$ & enrollment & 7203 & 7447 \\
w & average salary & 49.91 & 6.55 \\
sf & student faculty ratios & 13.95 & 4.90 \\
rf & sponsored research dollars faculty ratio & 17.24 & 17.42 \\
pgp & post-graduate student percentage & 10.1 & 14.81 \\
labp & laboratory student percentage & 22.9 & 21.58 \\
ptep & part-time enrollment percentage & 62.7 & 56.9 \\
instr & instruction and non-sponsored & 6.98 & 4.37 \\
& research cost per student & & \\
lib & library cost per student & .82 & .78 \\
comp & computer cost per student & .26 & .21 \\
adm & administration cost & 1.29 & 1.57 \\
phy & physical plant cost per student & 1.70 & 2.27
\end{tabular}

* All dollar amounts are in thousands 
the idea that income may determine expenditures for non-profit maximizing institutions. In particular, since universities are provincially funded, differences in expenditures per student may reflect systematic differences in provincial funding. To explore this possibility, dummy variables representing the individual provinces were added to the regression equation and regression analysis performed. The results showed no significant differences among the provinces in costs per student. ${ }^{8}$

\section{Regression Results}

The regression results are presented in Table 2 for all unit cost variables introduced. ${ }^{9}$ The first focus was on the results for overall costs per student (lac) which are shown in the first two columns. In general, the results were as expected. In particular, the result for the enrollment variable indicated declining unit cost as enrollment increases (i.e., economies of scale). In addition, universities with higher wages, post-graduate proportions ( $p g p)$, research intensities and lower student-faculty ratios had higher unit costs. Only the variables representing percentages of laboratory students and percentages of part-time students were insignificant at the five percent level. However, the insignificance of labp appeared to be due to collinearity with the research variable, since with rf omitted the coefficient for labp becomes positive and significant at the one percent level. This result is shown in column $2 .^{10}$

The role of student mix is further highlighted by comparing the cost per student predicted by the regression for a representative liberal arts undergraduate institution ( $l a b p$ and $p g p$ are zero) with cost per student for a university with mean levels of labp and pgp. At the mean enrollment of 7,203 students and mean levels for the remaining control variables, the regression predicted cost per student for the liberal arts institution was $\$ 10,392$ which is 85.9 percent of the predicted cost for a university with mean levels of $p g p$ and $l a b p$.

To interpret better the meaning of the coefficients, note that because the dependent variable is in logarithmic form, each coefficient is the proportional change in costs per student for a one unit change in the coefficient's variable. For example, in the first regression of Table 2 a one unit increase in the studentfaculty ratio from the mean of 13.95 to 14.95 would reduce costs per student proportionally by .057 or, in percentage terms, by 5.7 percent. By comparison, a one thousand dollar increase in the average faculty wage increased cost per student by 1.3 percent while a one percentage point increase in pgp increased cost per student by .60 percent. 
Table 2

Regression Results

\begin{tabular}{lccccccc}
\hline & LAC & LAC & LINSTR & LADM & LPHY & LLIB & LCOM $^{*}$ \\
\hline Intercept & 2.49 & 2.38 & 1.55 & .08 & .64 & -.43 & -1.29 \\
& $(12.64)$ & $(13.16)$ & $(8.24)$ & $(.21)$ & $(1.38)$ & $(1.40)$ & $(1.11)$ \\
\hline l/e & 112.0 & 107.4 & 72.6 & 220.6 & 158.1 & 82.5 & -261.2 \\
& $(9.72)$ & $(9.36)$ & $(7.18)$ & $(6.61)$ & $(6.01)$ & $(3.94)$ & $(1.73)$ \\
\hline w & .013 & .015 & .014 & .001 & .007 & .18 & -.0003 \\
& $(3.48)$ & $(4.64)$ & $(3.33)$ & $(.15)$ & $(.74)$ & $(2.39)$ & $(.01)$ \\
\hline sf & -.057 & -.057 & -.046 & -.031 & -.073 & -.064 & -.05 \\
& $(8.63)$ & $(8.94)$ & $(10.79)$ & $(1.73)$ & $(7.16)$ & $(7.08)$ & $(1.54)$ \\
\hline rf & .0044 & - & -.0006 & -.003 & -.004 & .0014 & -.0002 \\
& $(2.38)$ & & $(.37)$ & $(.77)$ & $(1.11)$ & $(.30)$ & $(.05)$ \\
\hline pgp & .0060 & .0069 & .0082 & .0026 & .0036 & .0082 & .0028 \\
& $(4.01)$ & $(4.55)$ & $(5.90)$ & $(.92)$ & $(.88)$ & $(2.21)$ & $(.51)$ \\
\hline labp & .0008 & .0034 & .0027 & -.0006 & .0074 & -.0053 & .013 \\
& $(.63)$ & $(3.18)$ & $(1.75)$ & $(.19)$ & $(2.11)$ & $(1.73)$ & $(1.98)$ \\
\hline ptep & -.003 & -.003 & .0005 & .0019 & .0002 & .0001 & .0067 \\
& $(.69)$ & $(.63)$ & $(1.63)$ & $(3.05)$ & $(.19)$ & $(.05)$ & $(3.31)$ \\
\hline Adjusted & & & & & & & \\
R ${ }^{2}$ & .90 & .89 & .86 & .77 & .66 & .77 & .26 \\
\hline
\end{tabular}

* Based on 51 observations since 10 institutions had negligible computing costs.

Before examining scale economies more closely, I analyzed the impact of the control variables on the other cost components. Not surprisingly, faculty wage rates were not significantly related to administration, physical plant and computing costs. They were related to library costs which would be consistent if library salary scales are related to faculty scales at an institution. Student-faculty ratios had a negative and, at the five percent level, significant impact on all unit cost variables except computing. The results for pgp and labp were plausible. Instructional and library costs were positively and significantly related at the one percent level to pgp, while increased percentages of laboratory students produced, at the ten percent level of significance, higher instructional cost and lower library cost per student and, at the five percent level of significance, 
higher physical plant and computing cost per student. Finally, the part-time enrollment variable only had a positive and significant effect, at the one percent level, on administration and computing cost and, at the eleven percent level of significance, a positive effect on instructional costs.

Returning to scale effects, the importance of scale economies can be neatly summarized with a scale elasticity. This measures the percentage increase in enrollment for a given percentage increase in total cost. ${ }^{11}$ If enrollment and costs increase by the same percentage, average costs do not change; hence, returns to scale are constant and the scale elasticity is unity. However, if enrollment increases more than costs, average cost per student fall, returns to scale are increasing and the scale elasticity is greater than one.

Scale elasticity calculations for all cost versions are reported in Table 3 . In each case, a scale elasticity was calculated for mean enrollment 7,203 students and for representatively small and large universities with enrollments equal to one-quarter and four times the sample mean. The results for total cost per student (lac) revealed that savings from enrollment expansions were greatest for smaller universities and were almost fully exploited for a representatively large university. For example, enrollment would increase 6.6 percent more than costs at a scale of 1,801 students but only .4 percent more at a scale of 28,812 students. This indicates that larger universities have, by and large, exhausted available scale economies.

Which components of cost are subject to the greatest scale effects? This is indicated by the scale elasticity numbers for the various cost components. Not surprisingly, physical plant and administrative expenditures, which are generally thought to have relatively high fixed costs, showed scale effects greater than for lac, while instructional and library expenditures showed effects less than observed for lac. The numbers for computing costs were less than one, indicating higher computing cost per student for larger institutions. However, only the number for the smallest enrollment $(1,801)$ was significantly less than one (constant returns to scale) at the five percent level.

Finally, another way to examine scale economies is to compute the cost per student predicted by the regression equation at different enrollments. For mean values of the control variables, the average cost per student predicted by the regression equation from representatively small to large were $\$ 12,676, \$ 12,098$ and $\$ 11,958$. This was a 6 percent range in average cost, but only a 1.2 percent range from mean size to representatively large size. ${ }^{12}$ 
Table 3

$\underline{\text { Scale Elasticities }}$

\begin{tabular}{lccc}
\hline & \multicolumn{3}{c}{ Enrollment* } \\
& 1,801 & 7,203 & 28,812 \\
\hline LAC & 1.066 & 1.016 & 1.004 \\
LINST & 1.042 & 1.010 & 1.003 \\
LADM & 1.140 & 1.032 & 1.008 \\
LPHY & 1.096 & 1.022 & 1.006 \\
LLIB & 1.048 & 1.012 & 1.003 \\
LCOM & .873 & .965 & .991 \\
\hline
\end{tabular}

* All figures except for LCOM are significantly greater than one at the one percent level. The LCOM figures are significantly different from one at the five percent level only when enrollment is 1801 . Standard errors for the scale elasticity statistic were computed with the analyz precedure of the TSP software program.

\section{Discussion}

The main conclusions from the regressions are that economies of scale apply to Canadian universities. The savings from enrollment increases are larger for smaller universities. Furthermore, costs per student are positively related to faculty salaries, faculty research intensity and the proportion of students in graduate programs and scientific disciplines.

Although the results appear reasonable, some of the usual caveats that apply to empirical work should be mentioned. In particular, important variables such as student enrollment and sponsored research expenditures per faculty member are only proxies for underlying student learning and research output (e.g., publications), and variables such as full-time faculty may not always be measured in the same way by reporting institutions. Better, more detailed data is the usual prescription for these measurement problems. ${ }^{13}$

Accepting the results at face value, what are the policy implications? The scale economy results suggest that restructuring the university sector into fewer but larger institutions can save dollars. This is effectively the conclusion of the Nova Scotia government which has mandated a rationalization of the eleven universities in its higher education sector. The results also suggest that the greatest savings would come from restructuring smaller institutions since larger 
universities have, by and large, exhausted all economies of scale. In fact, diseconomies of scale cannot be ruled out if universities were to grow beyond the largest scale observed in the sample.

Because there are cost savings from larger scale does not itself indicate that a reconfiguration is desirable policy, however. There are trade-offs. For example, there are benefits from having more universities which are strategically located to serve local communities through public services such as expanding knowledge about local areas and providing independent social comment about local issues. ${ }^{14}$ More generally, the presence of a university in a local community can add to the quality of that community's life and the productivity of its workforce.

The question of trade-offs also arises when we examine the cost implications of other variables. For example, to know that a one unit increase in the student-faculty ratio will reduce cost per student by 5.7 percent is not enough to guide policy without balancing this gain against the decline in quality of instruction that may ensue. Similar points apply to wages and research emphasis. Reducing wages saves dollars but adversely affects the quality of faculty that one can attract, while a lower research emphasis will reduce research output at some cost to society.

All of this is not to argue that cost effects such as those identified are unimportant, but only that cost effects by themselves are only part of the policy equation.

\section{Notes}

1 One exception is Hettich (1971) who examines productivity trends by relating students graduated to expenditures for the period 1956 to 1968.

2 Proulx (1973) in his review of cost studies in Canadian postsecondary education specifically points to the need for research on university cost functions.

3 There are two other expenditure categories: expenses for noncredit instruction and plant expenditures. These were not included as part of total costs. The first was omitted because noncredit enrollment is not included in enrollment figures. The second was excluded because it measures new construction costs which can vary dramatically from year to year and do not, in any event, measure operating capital cost (i.e., an imputed cost for depreciation and rental of buildings).

4 Following Robidoux and Lester (1988), four least squares enrollment variants were attempted. The first used both $e$ and $V e$; the second used only $e$; the third, only $V e$; and the fourth, neither $e$ or $/ / e$. With appropriately signed coefficients these allow the plot of average cost against enrollment to be U-shaped, negatively sloped or positively 
sloped. Based on the highest adjusted R-squared (Theil, 1971, p. 543) the $V e$ version was consistently superior for this and other versions of average cost.

5 Since this is a national sample, inclusion of faculty salaries is important because institutions in different regions may face different labour costs. Ideally, if one were available, a regional cost index for university inputs should be used. There is also a measurement error in the student-faculty ratio since it ignores part-time faculty for which no data were available

6 Sponsored research dollars are an imperfect proxy because not all research is sponsored; not all sponsored research leads to research output; and because there are differences in the cost of doing research among the disciplines. This last point means that this measure may underestimate the research undertaken at liberal arts institutions.

7 Another approach to part-time enrollment is to weight part-time enrollment by a number less than one and add this to full-time enrollment to measure the scale of a university. This route was not followed for two reasons. First, there is no clear common definition of a part-time student. Statistics Canada simply accepts the figures supplied by the reporting institutions. Second, full-time enrollment is probably a better measure of scale of operations, whereas part-time enrollment measures, in part, the degree to which a particular scale is utilized.

8 When defining the provincial dummies, Prince Edward Island and Newfoundland, because each had only one institution, were grouped with New Brunswick.

9 Since heteroscedasticity was indicated based on the test of White (1980), the standard errors were adjusted using White's heteroscedasticity-consistent variancecovariance matrix.

10 The simple correlation between lapd and $r f$ is .84. Omission of $r f$ for the other average cost components does not materially alter the results.

11 Algebraically, the scale elasticity is $(d C / C) /(d e / e)$, where $C$ is total cost. For regression (1) in Table 2 this simplifies to $1 /(1-112 / e)$.

12 How do these results compare to U.S. findings? Comparison are difficult. One reason is that the typical U.S. study does not have as many control variables as this study, instead choosing to focus on samples of what should be similar institutions, e.g., four-year institutions. Brinkman and Leslie (1986) conclude that the weight of the evidence is that substantial scale economies are most likely at low enrollment levels. For example, for educational and general expenditures they conclude that a three to four fold enrollment increase for small schools ( 5 - 600 students) would reduce per student costs 23 percent. This is considerably larger than what we observe.

13 It may be possible in the future to develop better measures of variables, such as research output, by cataloguing and weighting publications, but developing better measures of student learning is a much more daunting task.

14 In Nova Scotia, part of the problem may be that six of the institutions are located in one community - Halifax. 


\section{References}

Brinkman, P., \& Leslie, L. (1986). Economies of scale in higher education: Sixty years of research. Review of Higher Education, 10, 1-28.

Canadian Association of University Business Officers. (1987). Financial statistics of universities and colleges, 1986-7. Ottawa: Association of Universities and Colleges of Canada.

Hettich, W. (1971). Expenditures, output and productivity in Canadian university education. Ottawa: Economic Council of Canada.

Proulx, P. (1973). Cost studies in post-secondary education - Canada. Stoa, 3(1), 5-16.

Robidoux, B., \& Lester, J. (1988). Econometric estimates of scale economies in Canadian manufacturing. Working Paper 88-4, Ottawa: Department of Finance.

Statistics Canada. (1988). Universities: Enrollment and degrees, 1986. Catalogue 81204. Ottawa: Minister of Supply and Services.

Statistics Canada. (1989). Salaries and salary Scales of full-time teaching staff at Canadian universities, 1986-87. Catalogue 81-258. Ottawa: Minister of Supply and Services.

Statistics Canada. (1990). University enrollment by institution, registration status, level and field of study, 1986-7. Unpublished document. Ottawa: Minister of Supply and Services.

Theil, Henri. (1971). Principles of econometrics. New York: Wiley.

White, H. (1980). A heteroscedastic-consistent covariance matrix estimator and a direct test for heteroscedasticity. Econometrica, 48, 817-38. 